IN PRACTICE

\title{
Changing the prescribing patterns of sexually transmitted infections in the White Nile Region of Sudan
}

\author{
I B Eltayeb, A I Awad, M S Mohamed-Salih, M A Daffa-Alla, M B Ahmed, M A Ogail, L Matowe
}

Sex Transm Infect 2005;81:426-427. doi: 10.1136/sti.2004.014001

Background: The number of inappropriate prescriptions for sexually transmitted infections (STIs) in Sudan is suspected to be high. Simple multifaceted interventions directed at prescribers may improve prescribing patterns in the Sudan. Objective: To evaluate the effect of multifaceted interventions on prescribing for STIs in the White Nile State, Sudan.

Methods: The study involved 20 health centres randomly assigned to four different multifaceted interventions to improve prescribing.

Results: Prescriber targeted interventions involving audit and feedback together with academic detailing and practice guidelines reduced the number of inappropriate prescriptions by $50 \%(p<0.001)$. Audit and feedback together with seminars and practice guidelines reduced inappropriate prescriptions by $43 \%(p<0.001)$. Audit and feedback alone reduced inappropriate prescriptions by $16 \%(p=0.127)$.

Conclusion: Prescribing for STls in the White Nile State of Sudan needs improving. Multifaceted interventions appear effective in improving prescribing.

$\mathrm{S}$ exually transmitted infections (STIs) are a major public health problem worldwide and lately have become more consequential because of their facilitation of the transmission of HIV. ${ }^{1}$ Internationally, there is consensus that their control, including appropriate management of STIs, is one of the primary strategies for reducing HIV infections. ${ }^{2}$ In Sudan, the true prevalence of STIs is unknown but estimated to be high. In addition, there is a suspicion that prescribing for these infections is largely inappropriate. Multifaceted prescriber targeted interventions have been reported as effective in improving prescribing in developed countries. ${ }^{3}$ Such findings have not been demonstrated in Sudan. In this study the effect of multifaceted interventions on prescribing for STIs in the White Nile Region of Sudan was evaluated.

\section{METHODS}

Study setting and participants

The study was carried out in the White Nile State in central Sudan. In Sudan, the majority of people with general illnesses present at government health centres. This study was carried out in 20 such health centres, in which 18 medical officers and 19 medical assistants were responsible for prescribing.

\section{Interventions}

The 20 health centres were randomly allocated to receive no intervention, or any of the three interventions described in table 1.

\section{Data collection}

Thirty prescriptions for STIs were collected from each health centre before the intervention and 30 were collected
2 months after the intervention. From each prescription, data were abstracted on the prescriber's qualification, patient details, diagnosis, the drug prescribed, drug dose, and duration of therapy. Each prescription was evaluated by four prescribing experts for appropriateness of therapy based on WHO prescribing guidelines. ${ }^{4}$

\section{Data analysis}

Data were analysed using SPSS for Windows version 12.0. The differences within each group before and after intervention and those within the control group before and after intervention were compared using one way repeated measures analysis of variance (ANOVA). The mean difference was significant at $\mathrm{p}<0.05$.

\section{RESULTS}

Results are presented in table 2. The prescribing patterns among the study groups were similar at baseline. Preintervention study results showed high proportions of inappropriate prescriptions. Multifaceted interventions appeared effective.

\section{DISCUSSION}

We have shown that prescribing for STIs in Sudan is largely inappropriate. This may results in increased morbidity and mortality. Prescribing inadequate doses of antibiotics or prescribing them for an inadequate duration of therapy should raise some concern internationally with regard to antimicrobial resistance. Inappropriate antibiotic use has been documented as one of the major causes of antimicrobial resistance. ${ }^{5}$

Inappropriate prescribing in Sudan could be the result of non-availability of appropriate drugs or to improper training of prescribers. During discussions with prescribers during outreach programmes it was apparent that inadequate knowledge was the main factor contributing to inappropriate

Table 1 Intervention groups

Group Intervention

I Prescribers in this group received no intervention

II Prescribers in this group received, with explanation, graphical results of 3-4 months of audits of prescribing patterns within the region and within each health centre (audit and feedback)

III Prescribers in this group received audit and feedback; a copy of a prescribing guideline adapted by researchers from the WHO guideline for the effective management of $\mathrm{STls}^{4}$ and attended two seminars on prescribing conducted by experts in prescribing

IV Prescribers in this group received audit and feedback plus routine face to face educational meetings with prescribing experts (academic detailing). In addition, this group also received a copy of the prescribing guideline described above 
Table 2 Number (mean (SD)) of inappropriate prescriptions

\begin{tabular}{|c|c|c|c|c|}
\hline & $\begin{array}{l}\text { Pre- } \\
\text { intervention }\end{array}$ & $\begin{array}{l}\text { Post- } \\
\text { intervention }\end{array}$ & $\begin{array}{l}\text { Intervention } \\
\text { effect } \\
(95 \% \mathrm{Cl})\end{array}$ & p Value \\
\hline \multicolumn{5}{|c|}{ Number of inappropriate prescriptions according to diagnosis } \\
\hline Group I & $27.6(2.1)$ & $27.2(2.6)$ & & \\
\hline Group II & $26.8(3.9)$ & $22.6(1.1)$ & $3.8(-1.2$ to 8.8$)$ & 0.127 \\
\hline Group III & $28.0(2.5)$ & $16.0(2.6)$ & $11.6(6.6$ to 16.7$)$ & $<0.001$ \\
\hline Group IV & $29.2(0.8)$ & $14.6(2.5)$ & $14.2(9.2$ to 19.2$)$ & $<0.001$ \\
\hline \multicolumn{5}{|c|}{ Number of prescriptions with inappropriate dose and/or duration of therapy } \\
\hline Group I & $29.6(0.5)$ & $29.8(0.4)$ & & \\
\hline Group II & $29.4(1.3)$ & $26.4(4.0)$ & $3.2(0.3$ to 6.1$)$ & 0.034 \\
\hline Group III & $29.4(1.3)$ & $20.0(2.0)$ & 9.6 (6.7 to 12.5$)$ & $<0.001$ \\
\hline Group IV & $29.4(1.3)$ & $18.4(1.6)$ & $11.2(8.3$ to 14.1$)$ & $<0.001$ \\
\hline
\end{tabular}

\section{Key messages}

- Inappropriate prescribing for STIs in Sudan

- Limited resources appear to promote inappropriate prescribing

- Multifaceted interventions appear effective in improving prescribing in Sudan

prescribing. There is thus need for more training of prescribers in Sudan.

Lack of resources is also a contributing factor to inappropriate prescribing. Faced with a situation where a prescriber has to choose between sending a patient away with nothing for an infection or prescribing a poor alternative, a physician would most likely opt for the latter. An alternative approach would be for prescribers to prescribe the correct medicine and ask the patients to find the medicines themselves. A major drawback with this approach is that very few in Sudan could afford to purchase alternative medicines.

This study has confirmed that multifaceted interventions are effective in changing prescribing patterns in developing countries. Academic detailing, however, would present problems in developing countries because of its resource intensiveness. Reinforcement seminars, which were proved effective in this study, appear a cheaper and more practical alternative.

A potential weakness of this study is the small number of prescriptions evaluated. This was due to the limited resources available. The WHO, however, recommends 30 prescriptions per health facility as adequate to draw meaningful conclusions for such studies. ${ }^{6}$

Prescribing for STIs in the White Nile State in Sudan is largely inappropriate. Multifaceted interventions appear effective in improving prescribing.

\section{CONTRIBUTORS}

IBE, study perception, design, supervision; evaluation and writing; AIA, study perception, design, supervision; evaluation, data collection, data analysis, and writing; MSM-S, study perception, design, data collection; data analysis, and writing; MAD-A, data collection; MBA, data collection; MAO, data collection; LM, study evaluation, results analysis and writing.

\section{ACKNOWLEDGEMENTS}

We acknowledge the receipt of financial support from Alimam Almahdi University. We thank the health authorities and the health centres staff in the White Nile State for their assistance.

\section{Authors' affiliations}

I B Eltayeb, Department of Pharmacology, Faculty of Pharmacy, University of Khartoum, Sudan

A I Awad, L Matowe, Department of Pharmacy Practice, Faculty of Pharmacy, Kuwait University, Kuwait

M S Mohamed-Salih, M A Daffa-Alla, M B Ahmed, M A Ogail,

Departments of Pharmacology, Dermatology and Obstetrics and Gynaecology, Faculty of Medicine, Alimam Almahdi University Kosti, Sudan

Conflicts of interest: There are no potential conflicts of interest for any of the authors.

Correspondence to: Awad A I, Department of Pharmacy Practice, Faculty of Pharmacy, Kuwait University, Kuwait; amoneim@hsc.edu.kw

Accepted for publication 31 January 2005

\section{REFERENCES}

1 Cohen MS. Sexually transmitted diseases enhance HIV transmission: no longer a hypothesis. Lancet 1998;351(Suppl III):5-7.

2 Grosskurth H, Mosha F, Todd J, et al. Impact of improved treatment of sexually transmitted diseases on HIV-1 infection in rural Tanzania: a randomised controlled trial. Lancet 1995;346:530-6.

3 Grimshaw JM, Thomas RE, MacLennan G, et al. Effectiveness and efficiency of guideline dissemination and implementation strategies. Health Technol Assess 2004;8: 1-72.

4 World Health Organization. Guidelines for the management of sexually transmitted infections, WHO/HIV-AIDS/2001.01; WHO/RHR/01.10. Geneva: WHO).

5 O'Brien TF. Global surveillance of antibiotic resistance. N Engl J Med 1992;326:339-40.

6 World Health Organization. How to investigate drug use in health facilities: selected drug use indicators, DAP/93., 1993;93.1:1-87, Geneva: WHO. 